\title{
Analysis of the Chemical Safety Facility Investment Performance in China
}

\author{
Kang Sun, Long Bai, Xiaohong Li \\ Center for Studies of Marine Economy and Sustainable Development, Liaoning Normal University, \\ Dalian, China \\ Email: sunkangdl@163.com
}

Received 12 January 2015; accepted 27 January 2015; published 30 January 2015

Copyright $@ 2015$ by authors and Scientific Research Publishing Inc.

This work is licensed under the Creative Commons Attribution International License (CC BY). http://creativecommons.org/licenses/by/4.0/

(c) $\underset{\mathrm{EY}}{\mathrm{E}}$ Open Access

\begin{abstract}
This paper adopts the accident incidence, the gross industry output value, the investment in safety facilities, and per capita wage of employment as the indexes to empirically analyze the investment performance of chemical safety facilities using time series data by VECM in China. The empirical results indicate that for China's chemical industry, increasing investment fails to improve the short-term safety level significantly because of the offsetting behavior of workers. Over the long term, the offsetting behavior tends to disappear, and the chemical accident incidence can be decreased through increasing investment. Poor safety awareness among workers is one of the causes of accident incidences. The conclusions provide theoretical support for China to perfect chemical industry safety management.
\end{abstract}

\section{Keywords}

Chemical Safety Management, Peltzman Effect, Offsetting Behavior, VECM

\section{Introduction}

With the birth of chemical industry, controversy arose because of the industry's high risk to human safety and to the environment. In recent decades, hazardous chemical accidents have become a worldwide problem. Many international conventions relating to the chemical industry have been legislated, including regulations, policies, and industry management systems, such as the Rotterdam Convention (1998), the Stockholm Convention (2001), the UNEP (United Nations Environment Programme) Strategic Approach to International Chemicals Management (1998), and the EU (European Union) directive on Registration, Evaluation, Authorization and Restriction of Chemicals (REACH, 2007). Over the past 20 years, China has become a major international player in the chemical industry. Because of the rapid development of China's chemical industry, it has become the pillar industry 
of the national economy. Consequently, hazardous chemical accidents happen frequently, often engendering secondary disasters. Secondary disasters also pose big threats to human safety and health. The safety, health, and environmental problems caused by hazardous chemical accidents are increasing. The high frequency of chemical accidents has caused serious social problems in China. China has recently enacted more than 200 laws, administrative regulations, and departmental rules for its chemical industry. This intensification of management is unprecedented, but it still cannot stop the rise of chemical accidents year by year [1]. Thus, it is necessary to analyze the safety management effect empirically for China's chemical industry.

Most scholars used econometric analysis methods to research how the laws and regulations strengthened by safety regulatory organization influence the number of safety accidents brought by production and safety regulation effects empirically. Smith (1979) suggested that OSHA (Occupational Safety and Health Administration) policies were effective after analyzing the impact of its inspection on manufacturing injury rates over the period of 1973-1974 [2]. Gray and Scholz (1993) analyzed the industry panel data of 1979-1985 and concluded that OSHA policies reduced workplace fatalities by 22\% [3]. In addition, Beck and Alford [4] (1980), Carmichael [5] (1986), and Weil [6] (1996) also deemed safety regulation was effective. Nevertheless, the result of Viscusi's [7] [8] $(1979,1992)$ study was that the more the regulation was promulgated, the more deaths were caused through researching the U.S. government's safety and health regulation policy. Other scholars [9] [10] found that the regulation effect was unsatisfactory due to the regulatory capture phenomenon. The extant literature about chemical safety mainly focuses on accident disposal [11], accident statistical analysis [12], and the domino effect [13]. The literature in relation to the cause of chemical accidents which happened frequently is relatively lacking, especially empirical analysis in China.

In this paper, an empirical test on the investment performance of chemical safety facilities will be implemented to talk about the cause of the chemical accidents happening frequently through analyzing the dynamic relationship between the investment and the performance of chemical safety facilities, using the time series data by VECM (Vector Error Correction Model).

\section{Selection Criteria and Data}

The general empirical analysis approach for regulation effect is to do a regression of the regulation behavior index to the regulation effect index, then test the significance and direction of the influence. Due to the particularity and complexity of the chemical industry, there are many factors that influence the chemical accident incidence. In this paper, index selection is mainly on the basis of existing literature. For instance, safety inspections and fines of factories had been selected as regulation behavior; workplace accident mortality had been selected as regulation effect by Klick and Stratmann (2003) in their research using the data provided by the OSHA [14]. Similarly, in this paper, in order to highlight the chemical accidents which occurred frequently in China, the accident incidence is selected as investment performance index. In order to avoid the contingency factors of accident incidence increases, we normalize the index by 100 million Yuan output value. As for the investment of chemical safety facilities, we choose the investment in fixed assets to denote investment in chemical safety facilities $^{1}$. Following the Peltzman effect ${ }^{2}$, the workers' offsetting behavior is added to the empirical analysis. According to the rational economic man principle, per capita wage is selected to signify the workers' offsetting behavior. In addition to chemical enterprise behavior and worker behavior, other disturbance factors also influence the performance. In order to control these influences, the chemical gross industry output value index also is included in the empirical model.

This paper uses the annual data ${ }^{3}$ over the period 1981-2011 to identify the development trend of China's chemical accidents. Chemical industry refers to the Manufacture of Raw Chemical Materials and Chemical Products according to national economy classifications in China. The number of chemical accidents (1981-2000) is drawn from the book Selected Cases of Major Chemical Accidents, and the number of chemical accidents (2001-2011) is from the AIS (Accident Inquiry System) of the SAWS (State Administration of Work Safety) in

\footnotetext{
${ }^{1}$ The cause of choosing investment in fixed assets as the investment in safety facilities is that the statistical data of investment in safety facilities not listed separately in China, but included in the investment in fixed assets. Another reason is that good working environments and advanced equipment are the safety guarantees for workers.

${ }^{2}$ Peltzman (1975) found that the increase of auto safety equipment did not reduce traffic mortality in the study of automobile safety regulation effect because of the offsetting effect caused by the behavior of drivers. Klick and Stratmann (2003) defined this effect as the Peltzman effect.

${ }^{3}$ The data is not reported here to conserve space but is available from the author upon request.
} 
China. The data of chemical gross industry output value and investment in fixed assets are calculated from the China Statistical Yearbook (1982-2012). The data about per capita wage is calculated from the China Labor Statistical Yearbook (1991-2012). In order to eliminate price change effects on chemical gross industry output value and investment in fixed assets, we transform the data of chemical gross industry output value and investment in fixed assets to constant price of 1978 by the GDP deflator. To eliminate heteroscedasticity, except for accident incidence, all of the other variables take the form of natural logarithms. These four variables are respectively expressed by $S_{t}, V_{t}, I_{t}, W_{t}$.

\section{Empirical Results}

\subsection{Unit Root Test}

We begin our empirical analysis by testing for unit roots in the accident incidence $S_{t}$, gross industry output value $V_{t}$, investment in safety facilities $I_{t}$, and per capita wage $W_{t}$, because the integrational properties are crucial for the cointegration test and Granger causality test in VECM framework. We apply the conventional augmented Dickey and Fuller (ADF, 1979) test to establish the integrational properties of $S_{t}, V_{t}, I_{t}, W_{t}$. The calculated $t$-statistics together with the lag length selected using the SIC (Schwarz Information Criterion), as well as the critical value at $5 \%$ for the accident incidence $S_{t}$, gross industry output value $V_{t}$, investment in safety facilities $I_{t}$, and per capita wage $W_{t}$ series are reported in Table 1.

In Table 1, the calculated t-statistics for the levels of accident incidence $S_{t}$, gross industry output value $V_{t}$, investment in safety facilities $I_{t}$, and per capita wage $W_{t}$ series are greater than the critical value at the $5 \%$ significant level. This implies that we cannot reject the unit root null hypothesis. However, when we convert the accident incidence $S_{t}$, gross industry output value $V_{t}$, investment in safety facilities $I_{t}$, and per capita wage $W_{t}$ series into first difference and subject the series to the ADF test, the calculated $t$-statistic for all accident incidence $S_{t}$, gross industry output value $V_{t}$, investment in safety facilities $I_{t}$, and per capita wage $W_{t}$ is smaller than the critical value at the 5\% level. This implies that we can reject the unit root null hypothesis for all series in first difference form. As a result, all variables are integrated of order one. This paves the way for conducting tests for cointegration and Granger causality in a VECM framework later in the paper.

\subsection{Cointegration Test}

In order to examine the long-term relationship among the accident incidence $S_{t}$, gross industry output value $V_{t}$, investment in safety facilities $I_{t}$, and per capita wage $W_{t}$, we use the Johansen test method to perform a cointegration test. According to the AIC (Akaike Information Criterion) and SIC (Schwarz Information Criterion), the optimal number of lags for the Johansen cointegration test method is 3 . When the trace statistic is greater than the critical value at the 5\% significant level, reject the null hypothesis of "no cointegration"; When the trace statistic is smaller than the critical value at the $5 \%$ significant level, accept the null hypothesis. The test results are listed in Table 2.

As illustrated in Table 2, we accept the null hypothesis of "at most 3 cointegration relationships existed" among the accident incidence $S_{t}$, gross output value $V_{t}$, investment in safety facilities $I_{t}$, and per capita wage $W_{t}$ at the $5 \%$ significant level. The cointegration equation (two additional cointegration relationships are omitted because they are irrelevant to this paper) is estimated below (the standard errors are in parentheses):

$$
E C=S-\underset{(0.12454)}{1.219691 V}+\underset{(0.08206)}{0.2283725 I}+\underset{(0.13543)}{1.435979}
$$

Table 1. ADF unit root test results of $S_{t}, V_{t}, I_{t}, W_{t}$.

\begin{tabular}{ccccccccc}
\hline Variable & $S_{t}$ & $\Delta S_{t}$ & $V_{t}$ & $\Delta V_{t}$ & $I_{t}$ & $\Delta I_{t}$ & $W_{t}$ & $\Delta W_{t}$ \\
\hline$t$-statistic & -0.9979 & -5.3515 & -1.0925 & -5.3710 & -1.7326 & -2.3890 & 13.0112 & -4.3308 \\
[LL] & {$[0]$} & {$[0]$} & {$[0]$} & {$[0]$} & {$[1]$} & {$[0]$} & {$[0]$} & {$[0]$} \\
CV & -1.9525 & -1.9529 & -3.5684 & -3.5742 & -3.5742 & -1.9529 & -1.9525 & -3.5742 \\
\hline
\end{tabular}

Notes: LL denotes lag length, which is selected using the SIC automatically and CV denotes critical values at the $5 \%$ significant level. $\Delta$ is the difference operator. 
Table 2. Cointegration test results of $S_{t}, V_{t}, I_{t}, W_{t}$.

\begin{tabular}{ccccc}
\hline Hypothesized No. of CE(s) & Eigenvalue & Trace Statistic & 0.05 Critical Value & $P$ \\
\hline None $^{*}$ & 0.9323 & 146.8033 & 47.8561 & 0.0000 \\
At most 1 $^{*}$ & 0.7701 & 74.1057 & 29.7971 & 0.0000 \\
At most 2 & & & 15.4947 & 0.0000 \\
At most 3 & 0.7140 & 34.4119 & 3.8415 & 0.4346 \\
\hline
\end{tabular}

From Equation (1), in the long term, an increase in the gross output value $V_{t}$ has a positive effect on accident incidence $S_{t}$, and if the gross output value $V_{t}$ is increased by $1 \%$, the accident incidence $S_{t}$ will be increased by $1.22 \%$. An increase of investment in safety facilities $I_{t}$ and per capita wage $W_{t}$ both have negative effects on accident incidence $S_{t}$, and when investment in safety facilities $I_{t}$ and per capita wage $W_{t}$ are respectively increased by $1 \%$, the accident incidence $S_{t}$ will be decreased separately by $0.28 \%$ and $1.44 \%$. The negative effect of per capita wage $W_{t}$ is stronger than the positive effect of gross output value $V_{t}$.

\subsection{VECM}

A causality test is often used to analyze the causal relationship among the variables. When there is cointegration relationship among the variables, we can construct a VECM to get the regression equation including the error correction item. The Wald joint test is then used to test the significance of the coefficient both on the variables and the error correction item to judge the causality direction [15] [16] in the VECM framework. The lag length is equal to the lag length for the cointegration test. The general equation of VECM is expressed by:

$$
\Delta Y_{t}=\sum_{i=1}^{p} \Gamma_{i} \Delta y_{t-i}+\lambda E C_{t-1}+\varepsilon_{t}
$$

where $Y_{t}=\left[\begin{array}{llll}S_{t} & V_{t} & I_{t} & W_{t}\end{array}\right]^{\prime}, \quad \Gamma_{i}$ is the coefficient matrix, reflecting the impact made by short-term change of explaining variables to short-term change of explained variable. $E C_{t-1}$ is the error correction item, reflecting the long-term equilibrium relationship of variables. $\lambda$ is the coefficient vector of $E C_{t-1}$, reflecting the adjustment velocity from disequilibrium to equilibrium when it deviates from a long-term equilibrium state. $\varepsilon_{t}$ denotes random error vector.

The specific VECM equation ${ }^{4}$ in which accident incidence $S_{t}$ is the explained variable with gross industry output value $V_{t}$, investment in safety facilities $I_{t}$ and per capita wage $W_{t}$ as the explaining variable is:

$$
\begin{aligned}
\Delta S_{t} & =\left[\begin{array}{l}
-0.1976 \\
-0.0158 \\
-0.0134 \\
0.0712
\end{array}\right]\left[\begin{array}{llll}
\Delta S & \Delta V & \Delta I & \Delta W
\end{array}\right]_{t-1}+\left[\begin{array}{c}
-0.0510 \\
0.0100 \\
0.0062 \\
-0.0083
\end{array}\right]\left[\begin{array}{llll}
\Delta S & \Delta V & \Delta I & \Delta W
\end{array}\right]_{t-2} \\
& +\left[\begin{array}{c}
-0.2474 \\
-0.0279 \\
-0.0195 \\
0.1598
\end{array}\right]\left[\begin{array}{llll}
\Delta S & \Delta V & \Delta I & \Delta W
\end{array}\right]_{t-3}-0.0146 E C_{t-1}-0.0108 .
\end{aligned}
$$

where $E C_{t-1}=S_{t-1}-1.2197 V_{t-1}+0.2837 I_{t-1}+1.4360 W_{t-1}-3.3581$. From the Equation (3), the coefficient on $E C_{t-1}$ is -0.0146 , meaning that the adjustment degree of the disequilibrium for the previous year is the $1.46 \%$.

At the $5 \%$ significant level, use the Wald joint test on the equation in which accident incidence $S_{t}$ is the explained variable, with gross industry output value $V_{t}$, investment in safety facilities $I_{t}$ and per capita wage $W_{t}$ as explaining variables. The null hypothesis of the Wald joint test is that there is no granger causality

\footnotetext{
${ }^{4}$ The main purpose of this paper is to analyze the impact on accident incidence made by chemical gross industry output value, investment in safety facilities, and per capita wage. Thus, only the equation in which accident incidence is the explained variable is listed.
} 
between variables. When the probability value of the Wald joint test $\chi^{2}$ is greater than 0.05 , accept the null hypothesis; When the probability value of the Wald joint test $\chi^{2}$ is smaller than 0.05 , rejected the null hypothesis. The Wald joint test results are shown in Table 3.

The statistical significances of each coefficient in Table 3 indicate that at the 5\% significant level, all the null hypothesizes $\left(H_{0}\right)$ were rejected. Combined with the VECM equation interpretation, we know that in both the short and long term, the changes of gross industry output value $V_{t}$, investment in safety facilities $I_{t}$ and per capita wage $W_{t}$ are all the Granger causes of change in accident incidence $S_{t}$.

\subsection{Impulse Response Function}

Through impulse response function analysis, the path of influence affected by gross industry output value $V_{t}$, investment in safety facilities $I_{t}$ and per capita wage $W_{t}$ on current value and future value of accident incidence $S_{t}$ can be obtained. To avoid variable order affecting the results, we choose the generalized impulse response function to do impulse response function analysis. The impulse response curves are represented in Figure 1 and Figure 2. The horizontal axis denotes the period (here we report only 10 periods; increasing the period does not affect the conclusion), and the vertical axis denotes the response degree.

Figure 1 shows the curve of response of per capita wage $W_{t}$ to investment in safety facilities $I_{t}$ impulse. From Figure 1 we can demonstrate that, in the short term, the response of per capita wage $W_{t}$ to investment in

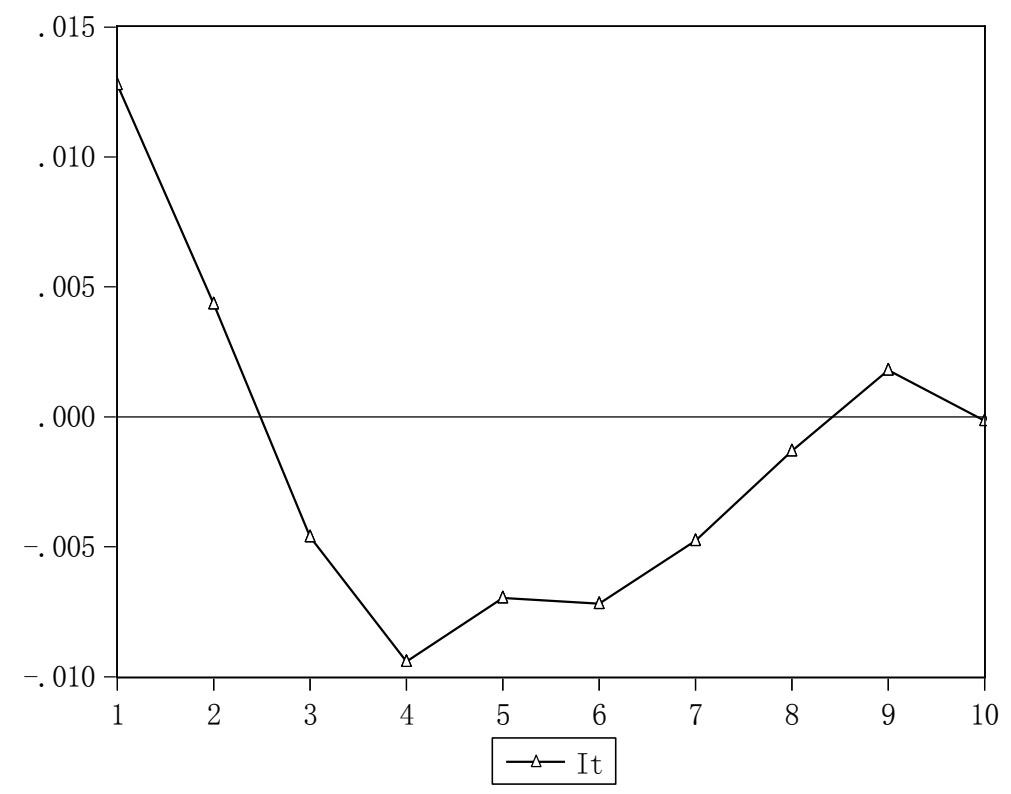

Figure 1. Curve of response of $W_{t}$ to $I_{t}$.

Table 3. The results of the Granger causality test of $S_{t}, V_{t}, I_{t}, W_{t}$.

\begin{tabular}{|c|c|c|c|c|c|c|}
\hline \multicolumn{7}{|c|}{ Test equation ${ }^{5}: \Delta S_{t}=\sum^{3}\left[\alpha_{1 i} \Delta S_{t-i}+\beta_{1 i} \Delta V_{t-i}+\gamma_{1 i} \Delta I_{t-i}+\delta_{1 i} \Delta W_{t-i}\right]+\lambda_{1} E C_{t-1}+\varepsilon_{1}$} \\
\hline \multirow{4}{*}{$\Delta S_{t}$} & & $\Delta V_{t}$ & $\Delta I_{t}$ & $\Delta W_{t}$ & Joint test & $E C$ test \\
\hline & $H_{0}$ & $\beta_{1 i}=0$ & $\gamma_{1 i}=0$ & $\delta_{1 i}=0$ & $\beta_{1 i}=\gamma_{1 i}=\delta_{1 i}=0$ & $\lambda_{1}=0$ \\
\hline & $\chi^{2}$ & 14.8771 & 8.3034 & 20.0818 & 42.7323 & 4.03778 \\
\hline & $P$ & 0.0019 & 0.0401 & 0.0002 & 0.0000 & 0.0445 \\
\hline
\end{tabular}

NOTE: $H_{0}$ indicates that the row variable doesn't cause the column variable; $P$ is the probability value of Wald joint test $\chi^{2}$.

${ }^{5}$ The main purpose of this paper is to analyze the impact on accident incidence made by chemical gross industry output value, investment in safety facilities and per capita wage. Therefore, only test the equation in which accident incidence is the explained variable. 


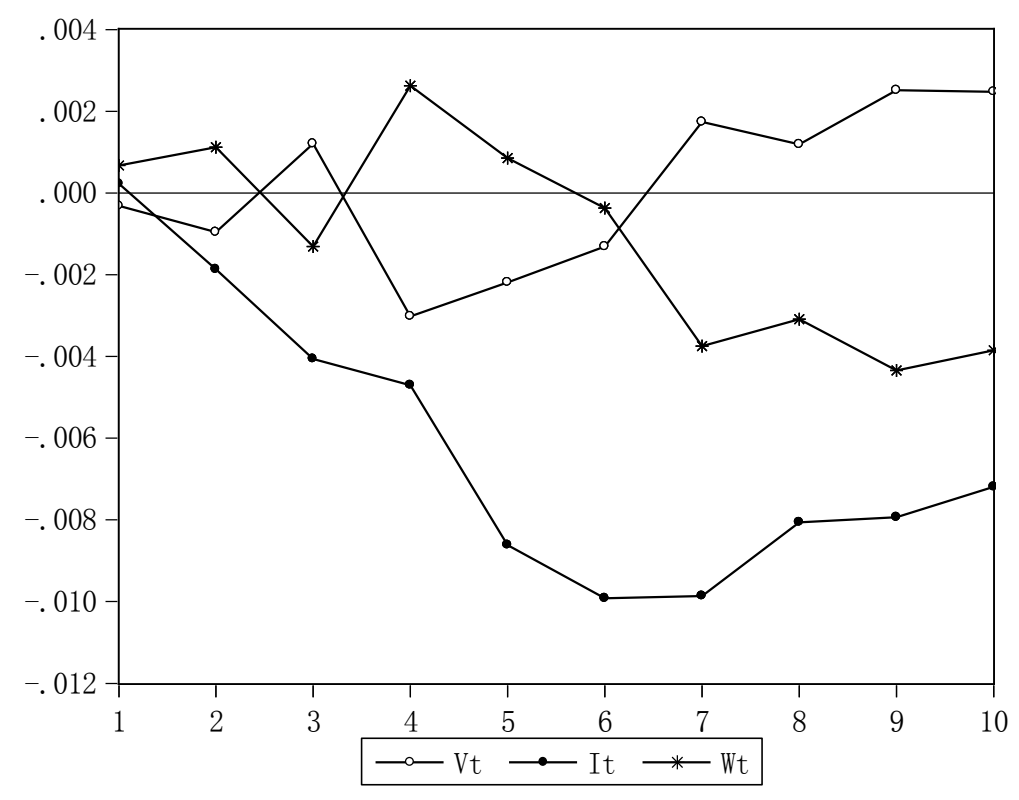

Figure 2. Curves of response of $S_{t}$ to $V_{t}, I_{t}, W_{t}$.

safety facilities $I_{t}$ impulse is positive. In the long term, the response is negative. For a positive information rush of $I_{t}$, the maximum positive response of $W_{t}$ is achieved in the first period. Starting from the third period, the response turns from positive to negative. The strongest negative response is in the fourth stage, subsequently decreasing gradually. That is, in the short term, an increase in investment in safety facilities will increase the per capita wage of workers. In the long run, the increase investment in safety facilities can reduce per capita wage.

Figure 2 shows the curves of response of accident incidence $S_{t}$ to gross industry output value $V_{t}$ impulse, investment in safety facilities $I_{t}$ impulse, and per capita wage $W_{t}$ impulse. From Figure 2 we can deduce: (1) in the short term, the response of accident incidence $S_{t}$ to gross industry output value $V_{t}$ is negative. In the long term, the response is positive. For a positive information rush of $V_{t}$, the maximum negative response of $S_{t}$ is achieved in the fourth period. From the seventh period, the response of $S_{t}$ to $V_{t}$ becomes positive. These results show that in the short term, the increase in chemical gross industry output value will reduce the accident incidence, but in the long term, the increase will cause the accident incidence to increase. (2) In the short term, the response of accident incidence $S_{t}$ to investment in safety facilities $I_{t}$ is positive. In the long term, the response is negative. For a positive information rush of $I_{t}$, the maximum positive response of $S_{t}$ is achieved in the first period. Beginning from the second period, the response becomes negative and continues to strengthen. From the seventh period, the response starts to weaken. That is, in the short term, the increase investment in safety facilities will increase the accident incidence. However, in the long term, the increase in investment in safety facilities will reduce accident incidence. (3) In the short term, the response of accident incidence $S_{t}$ to per capita wage $W_{t}$ impulse is positive. In the long term, the response is negative. For a positive information rush of $W_{t}$, the maximum positive response of $S_{t}$ is achieved in the fourth period. Then, the response is negative, and the maximum negative response of $S_{t}$ is achieved in the ninth period. Namely, in the short term, the increase in per capita wage will cause accident incidence to increase. In the long term, the increase in per capita wage will reduce accident incidence.

From the perspective of the chemical workers' safety awareness, workers tend to generate offsetting behavior, because of workers' behavior in regards to moral hazard. The workers' offsetting behavior is derived from the relatively low knowledge level of chemical workers. The main reason for chemical workers lack knowledge culture is that according to China's family planning policy, each urban family only has one child, and each rural family can have two children. The consequences of the one-child policy are as follows: first, the urban onlychild is spoiled and doesn't want to work at the chemical factory in which the working environment is poor; second, the vocational-technical schools in cities designed for chemical plant workers have been forced to close due to lack of students; third, in China, migrant workers ${ }^{6}$ have become the current primary labor in high-risk

${ }^{6}$ Refers to the agricultural registered permanent residents working at the local township enterprise or urban enterprise. 
industries such as the chemical industry, especially in private chemical enterprises. Because of migrant workers' education level is relatively low, when judging safety risk, they are more likely to generate offsetting behavior. In the short term, when the enterprises increase investment in safety facilities to provide a safer working environment for workers, the workers will be dependent on enterprise safety precautions excessively, thinking that their working environment is safe, thus reducing their safety awareness ${ }^{7}$. So, workers tend to increase labor efforts to earn higher wages by reducing safety efforts (assume that the worker will allocate his effort between wage effort and safety effort in this paper), leading to an offsetting effect. If the offsetting effect is strong enough, the accident incidence will increase conversely. Therefore, in the short term, with the increase in investment in safety facilities, per capita wage and accident incidence both increase. In the long term, with the improvement of the workers' risk prevention awareness level through strengthening education and training, when increasing investment in safety facilities, workers will be aware of the increase in potential risk, rather than believing that their working environment gets better. Thus, workers will transfer their effort to safety from wages, obtaining a higher safety level. That is, with the workers' offsetting behavior disappearing gradually, an increase in investment in safety facilities will eventually have the effect off reducing accident incidence.

\section{Case Study}

Dalian is located in the northeast coastal chemical industry area of China, and the chemical industry is developing rapidly. After the oil pipeline explosion on July 16, 2010 which shocked the world, the nation and the local government attached great importance to chemical safety. In 2010 and 2011, the government passed a total of 6 laws and regulations about hazardous chemicals (30, 32, 36, 40, 41, 42 in order), two times more than the sum of the past five years. Meanwhile, the Dalian government invested 20 million Yuan (investment in safety facilities) to improve the safety level of chemical companies, including the upgrade and reform of enterprise hazardous process automation control, with all the chemical enterprises within the district achieving the process automation control. This 20 million Yuan investment not only achieved the expected effect, but also increased the accident incidence.

On November 25, 2010, a toxic gases spill accident (including carbon oxide, hydrogen sulfide and so on) occurred in Carbon Chemical Co., Ltd. in Dalian, resulting in more than 20 workers, who were doing gymnastics close to the scene, suffering from toxic gas poisoning. The enterprise has sound safety rules and regulations, perfect safety operational procedures and security facilities. The cause of the accident was ash deposits in the gasifier, leading to the stopping of the compressor, and then the system stopped automatically. When the gases in the furnace burned insufficiently, toxic gases emitted directly through the torch. The direct cause of the accident was the workers' over-reliance on the automatic safety chain system. When deviant behavior occurred at the end of the safety chain, there was no human intervention, eventually leading to the gas leakage accident ${ }^{8}$.

On August 29, 2011, Dalian Petrochemical Company's refined oil storage tank exploded and caught fire. The incident occurred when the tubing outlet velocity of $\# 875$ tank reached $4.34 \mathrm{~m} / \mathrm{s}$, due to the floating plate without automatic floating, during the oil delivery operations of refined oil storage tanks. Due to exceeded safety limits, a large amount of static electricity was produced and discharged, igniting the mixture of oil mist, combustible gas and air, which exploded. This was a typical accident caused by violation of rules. When the tubing outlet velocity exceeded the safety limits, the workers didn't control the tubing outlet velocity within safe limits in accordance with the rules, but relied on automatic equipment operation fully, resulting in the storage tank exploding and catching fire.

During the 2010 and 2011, while safety regulation was enhanced, the number ${ }^{9}$ of the chemical accidents was 2.7 times more than the total of the previous two years in Dalian. And 62.5\% of 2010-2011 accidents belong to the "three violations" category. This indicates that the offsetting behavior is more serious in Dalian. Regulation enhancement did not reduce the accident incidence, but increased the accident incidence, due to workers relying too heavily on security facilities. The main reason is that, several years ago, the original chemical vocationaltechnical school in Dalian had been forced to close due to insufficient number of students. Migrant workers' safety training is insufficient and safety awareness is weak, which is the reason for serious chemical workers' offsetting behavior in Dalian. The case of Dalian further illustrates workers' offsetting behavior is the main cause of chemical accident increases.

\footnotetext{
${ }^{7}$ Viscusi (1979) through study found that when companies improve workers' working conditions and the quality of labor safety, workers' safety efforts will decline and the action level preventing risk will drop.

${ }^{8}$ See the two cases, Dalian Administration Bureau of Safety Working in China (2010-2011).

${ }^{9}$ The number of chemical accidents is taken from the China Chemical Safety Association.
} 


\section{Conclusion}

This paper adopts the chemical accident incidence, the chemical gross industry output value, investment in safety facilities of chemical industry, and per capita wage of chemical industry employment as the indexes to empirically analyze investment performance of chemical safety facilities using time series data over the period 1981-2011 by VECM. The empirical results indicate that for China's chemical industry, in the short term, increasing fails to improve the safety level significantly because of the offsetting behavior of the employees. Over the long term, the offsetting behavior tends to diminish, and the chemical accident incidence can be decreased by increasing the investment performance index. Poor safety awareness among workers is one of the causes of accident incidences. Therefore, making sure to heighten the chemical workers' safety awareness is one of the measures to improve the investment performance of chemical safety facilities in the short term.

\section{Funding}

Social Science Fund Project of Liaoning province (L13BJY033); Social Science Fund Project co-sponsored by province and ministry (13JJD790042).

\section{References}

[1] Sun, K. and Yang, H.M. (2012) Statistical Analysis of Dangerous Chemical Accidents in China. Fire Technology, 48, 331-341. http://dx.doi.org/10.1007/s10694-011-0224-y

[2] Smith, R.S. (1979) The Impact of OSHA Inspection on Manufacturing Injury Rates. Journal of Human Resource, 14, $145-170$

[3] Gray, W.B. and Scholz, J.T. (1993) Does Regulatory Enforcement Work? A Panel Analysis of OSHA Enforcement. Law \& Society Review, 27, 177-213. http://dx.doi.org/10.2307/3053754

[4] Lewis-Beck, M.S. and Alford, J.R. (1980) Can Government Regulate Safety? The Coal Mine Example. The American Political Science Review, 74, 745-756. http://dx.doi.org/10.2307/1958155

[5] Carmichael, H.L. (1986) Reputations for Safety: Mark Performance and Policy Remedies. Journal of Labor Economics, 4, 458-472. http://dx.doi.org/10.1086/298106

[6] Weil, D. (1996) If OSHA Is So Bad, Why Is Compliance So Good? The Rand Journal of Economics, 27, 618-640. http://dx.doi.org/10.2307/2555847

[7] Viscusi, K. (1992) Fatal Tradeoffs: Public and Private Responsibilities for Risk. Oxford University Press, New York, 50-171.

[8] Viscusi, K. (1979) The Impact of Occupation Safety and Health Regulation, 1973-1983. Bell Journal of Economics, 10, 117-140. http://dx.doi.org/10.2307/3003322

[9] Keiser, K.R. (1980) The New Regulation of Health and Safety. Political Science, 95, 479-491. http://dx.doi.org/10.2307/2150061

[10] Greenberg, E.S. (1985) Capitalism and the American Political Ideal. M. E. Sharpe, Armonk, 76-80.

[11] Reniers, G.L.L., et al. (2008) A Multiple Shutdown Method for Managing Evacuation in Case of Major Fire Accidents in Chemical Clusters. Journal of Hazardous Materials, 152, 750-756. http://dx.doi.org/10.1016/j.jhazmat.2007.07.040

[12] He, G.Z., et al. (2011) Managing Major Chemical Accidents in China: Towards Effective Risk Information. Journal of Hazardous Materials, 187, 171-181. http://dx.doi.org/10.1016/j.jhazmat.2011.01.017

[13] Zhang, X.M. and Chen, G.H. (2011) Modelin and Algorithm of Domino Effect in Chemical Industrial Parks Using Discrete Isolated Island Method. Safety Science, 49, 463-467. http://dx.doi.org/10.1016/j.ssci.2010.11.002

[14] Klick, J. and Stratmann, T. (2003) Offsetting Behavior in the Workplace. Working Paper, George Mason University, Feldstein.

[15] Feldstein, M. and Stock, J.H. (1994) The Use of a Monetary Aggregate to Target Nominal GDP. Monetary Policy, University of Chicago Press, Chicago, 7-69.

[16] Toda, H.Y. and Phillips, P.C.B. (1993) Vector Autoregressions and Causality. Econometrica, 61, 1367-1393. http://dx.doi.org/10.2307/2951647 
Scientific Research Publishing (SCIRP) is one of the largest Open Access journal publishers. It is currently publishing more than 200 open access, online, peer-reviewed journals covering a wide range of academic disciplines. SCIRP serves the worldwide academic communities and contributes to the progress and application of science with its publication.

Other selected journals from SCIRP are listed as below. Submit your manuscript to us via either submit@scirp.org or Online Submission Portal.
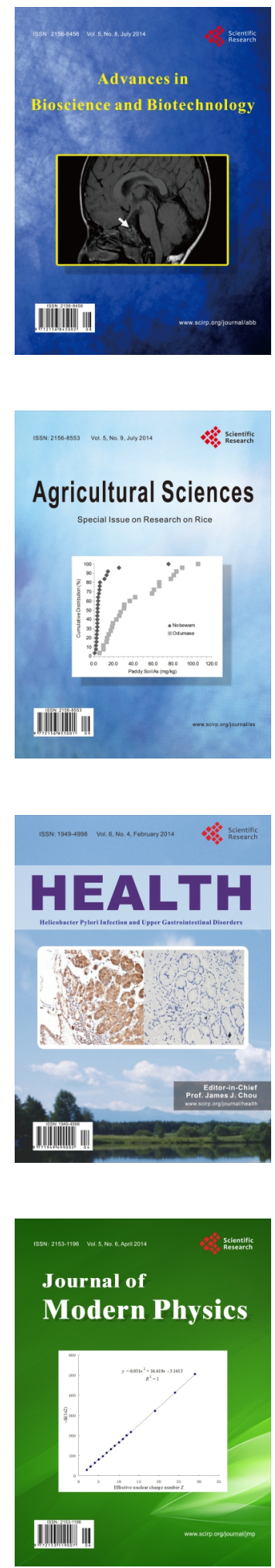
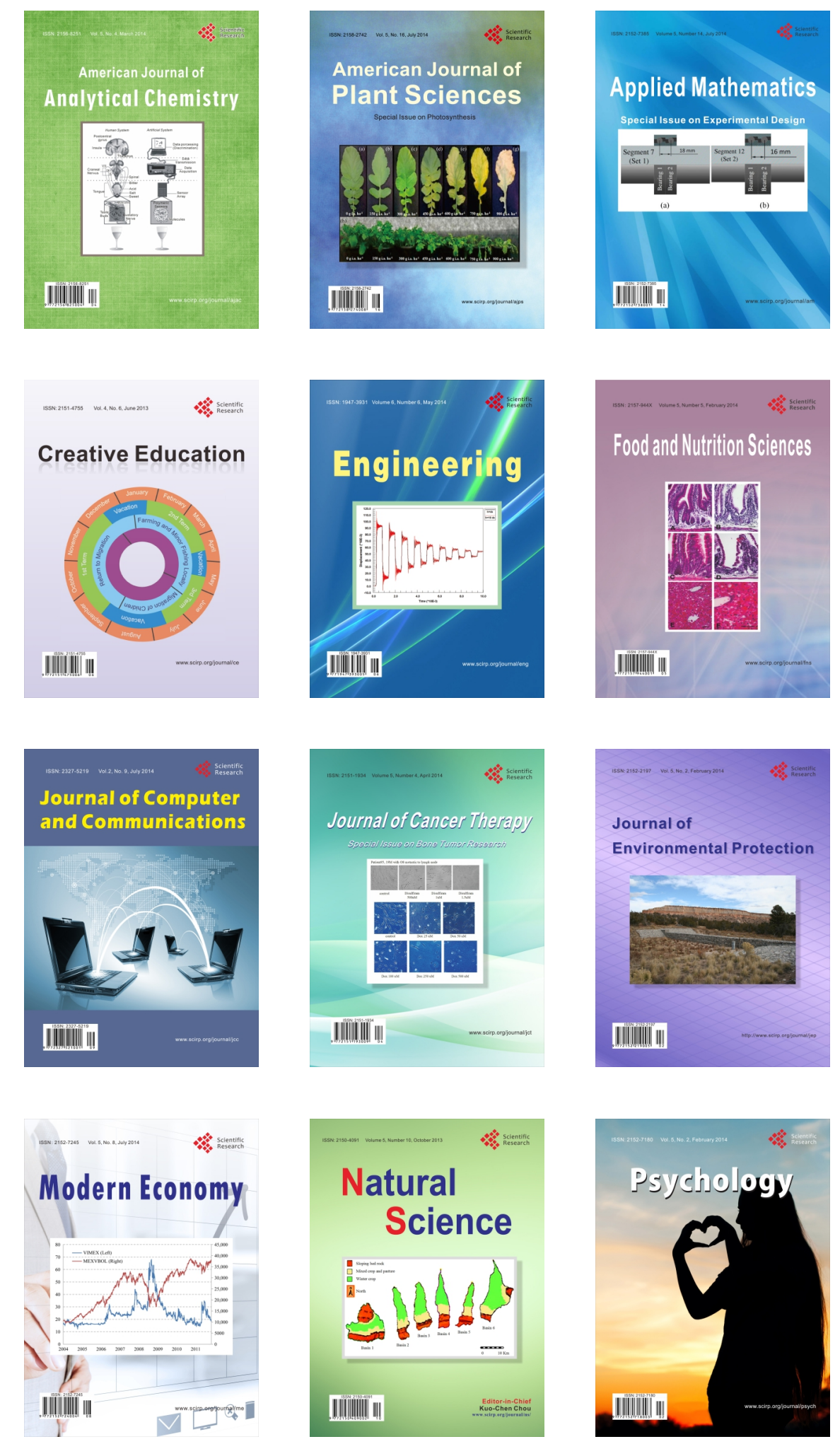